\title{
Social Science is key to effective climate change mitigation: A reply to Nature editorial
}

Sir,

In your editorial „How researchers can help fight climate change in 2022 and beyond” you rightly emphasize the value of emerging energy supply and end-use technologies for achieving much needed though highly ambitious GHG emission reductions. However, meeting this goal at the necessary speed is not solely a technical problem. There is a long history of promised technological solutions that never materialized. The same is true of public policy interventions. We can do better by integrating social science knowledge of why such technologies and interventions fall short and how to design implementable and scalable interventions that deliver GHG emission reductions. An integrated approach will enable better informed choices about technical and policy priorities and more effective implementation.

The time has come to take the potential contribution of the social sciences to climate change mitigation seriously. We cannot afford to pursue engineered optimality while ignoring the social systems underpinning the transition. Social trust, structured decision processes, and impartial rules are needed to build management systems both bottom-up and top-down ${ }^{1,2}$ and initiatives need to apply design principles developed in the social sciences for achieving the required changes in organizational and individual behavior ${ }^{3}$. Initiatives need also to consider distributional equity and the interests of potentially affected parties. Such engagement can ensure the social feasibility of otherwise promising technological initiatives. Successful climate change mitigation will be based on integrating understanding of technological systems with understanding of behavioral, economic, social, and political processes.

Signed by Felix Creutzig ${ }^{1 *}$, Thomas Dietz ${ }^{2}$, Kristian S. Nielsen ${ }^{3}$, Paul C. Stern ${ }^{4}$, Rachael Shwom ${ }^{5}$, Michael P. Vandenbergh ${ }^{6}$

\section{References}

1. Ostrom, E. Governing the commons: the evolution of institutions for collective action. (Cambridge, Cambridge University Press, 1990).

2. Rothstein, B. The Quality of Government: Corruption, Social Trust, and Inequality in International Perspective. (University of Chicago Press, 2011).

3. Stern, P. C., Janda, K. B., Brown, M. A., Steg, L., Vine, E. L., \& Lutzenhiser, L. Opportunities and insights for reducing fossil fuel consumption by households and organizations. Nature Energy 1, (2016).

1 creutzig@mcc-berlin.net; +49 303385537 -225; Mercator Research Institute on Global Commons and Climate Change, Berlin, Germany, ORCID: 0000-0002-5710-3348

2 tdietzvt@gmail.com; 1-517-353-8763; Michigan State University, East Lansing, MI, USA, ORCID: 0000-0001-9399-0784

${ }^{3}$ ksn27@cam.ac.uk; +44 (0)7518766729; University of Cambridge, Cambridge, United

Kingdom, ORCID: 0000-0002-8395-4007 
${ }^{4}$ pstern@seri-us.org; 1-607-846-0565; Social and Environmental Institute, Shelburne Falls, MA, USA, ORCID: 0000-0002-9481-3904

${ }^{5}$ shwomrac@sebs.rutgers.edu; 1-848-932-9235; Rutgers University, New Brunswick, New Jersey, USA, ORCID: 0000-0002-9648-1659

${ }^{6}$ michael.vandenbergh@ vanderbilt.edu; 1-615-322-6763; Vanderbilt University, Nashville, TN, USA, ORCID: 0000-0002-1629-7086

*corresponding author 